\title{
Verbs of Command and the Status of Their Embedded Complements in Chinese
}

\author{
Chak-Lam Colum Yip \\ University of Washington
}

\begin{abstract}
This paper argues against Yue's (1999) view that complements to verbs of commands (jiao 'to ask/to tell,' qing 'to request,' quan 'to persuade,' etc.) are embedded imperatives with a covert [+second person] subject pronoun. Evidence against the embedded imperative analysis include the presence of partial control, the absence of blocking effect in long-distance binding, the incompatibility between these complement clauses and the polite imperative marker qing, and the fact that Yue's proposed covert [+second person] pronoun cannot be made overt. Since verbs of commands participate in object control, the present proposal agrees with Zhu's (1982) treatment of verbs of command as pivotal verbs. Finally, complement clauses of verbs of command are not embedded imperatives as bie can also appear with third person subjects, which shows that the negator does not mark imperative but irrealis and deontic modality. Hence, its presence in complements of verbs of command does not lead to an embedded imperative analysis.
\end{abstract}

\section{Keywords}

embedded imperatives, pivotal constructions, imperative negator, object control, deontic modality

Studies in Chinese Linguistics, Volume 37, Number 2, 2016, 130-145 DOI: 10.1515/scl-2016-0006 (C2016 by T.T. Ng Chinese Language Research Centre, Institute of Chinese Studies, The Chinese University of Hong Kong 


\section{Introduction}

Pivotal constructions have been found throughout the history of the Chinese language. Yue (1999: 327) defines pivotal constructions as "complex sentence[s] with at least two verb phrases that contain a noun phrase - the pivot - which is at once the object of the preceding verb and the subject of the following verb." Although the term 'pivotal construction' in traditional Chinese grammar encompasses both object-control and ECM/raising structures, this paper focuses only on verbs of command (e.g. jiao 'to ask/to tell,' qing 'to request,' quan 'to persuade,' etc.) which participate in object-control, as in (1).

(1) a. Laoshi quan wo zuo gongke. teacher urge me do homework

'The teacher urged me to do homework.'

b. Laoshi quan wo ${ }_{i}\left[_{\mathrm{CP}} \mathrm{PRO}_{\mathrm{i}}\right.$ zuo gongke].

Yue (1999) argues that verbs of command in Chinese are not true pivotal verbs (or "object control verbs" in formal syntax) as they head embedded imperative clauses with covert [ + second person] subject pronouns. This view diverges slightly from Zhu's (1982) original treatment, and also assumes that there is no object control.

(2) Laoshi quan wo [ ${ }_{\mathrm{CP}}$ (ni) zuo gongke].

One of Yue's main arguments for the claim that the bracketed embedded clause is an imperative clause is that the imperative negator bie appears when the embedded clause is negated, as in (3).

(3) Laoshi quan wo [ ${ }_{\mathrm{CP}}$ bie zuo gongke]. teacher urge me NEG.imp do homework

'The teacher urged me not to do homework.'

The goal of this paper is twofold. First, based on historical and language-internal facts, this paper argues against the embedded imperative analysis in Yue (1999) and supports the view that verbs of command are object control verbs. Second, I argue that the negator bie does not only function as an imperative negator, but as a negator denoting deontic modality. The paper is structured as follows. Section 2 offers a summary of Yue's (1999) arguments for the embedded imperative analysis. Following that, counterarguments against Yue are presented in Section 3. In Section 4, it is argued that verbs of command in Chinese are object control verbs. Section 5 presents data showing that the so-called imperative negator does not always appear with a [+second person] subject and that this negator marks a deontic modality. Section 6 concludes the paper. 


\section{Yue (1999)'s embedded imperative analysis}

Yue (1999) argues that object control constructions involving verbs of command are not "true" pivotal constructions. She claims that simple negative marker $b u$ is used in declarative sentences, but the imperative negator bie appears when imperative clauses and complements of verbs of command are negated. In light of this, Yue proposes that complements of verbs of command are embedded imperatives.

(4) a. Ta bu he jiu.

He NEG drink alcohol

'He doesn't drink.'

b. (Ni) bie he jiu!

You NEG.imp drink alcohol

'(You) don't drink!'

c. Wo jiao ta bie he jiu.

I ask him NEG.imp drink alcohol

'I asked him not to drink alcohol.'

Furthermore, the sentential adverb qianwan 'by all means' only appears with the modal yao 'have to,' which Yue claims to be the affirmative marker used in imperative constructions. Again, the (qianwan) + yao pattern is observed in embedded complements of verbs of command.
a. $\mathrm{Ni}$ qianwan *(yao) he jiu.
You by all means have-to drink alcohol
'You have to drink, by all means!'
b. Wo jiao ta qianwan yao he jiu.
I ask him by all means have-to drink alcohol
'I told him to drink, by all means.'

Yue concludes that embedded complements of verbs of command must be imperative clauses. Since subjects of imperative sentences are always $[+$ second person] in Mandarin Chinese, Yue argues that there must be a covert second person subject pronoun in the underlying structure of the embedded complement. Following her assumptions, (6) would be the underlying form of (4c):

(6) Wo jiao ta [(ni) bie he jiu].

I ask him you NEG.imp drink alcohol 'I asked him not to drink alcohol.'

Yue extends her analysis of pivotal constructions involving verbs of command to Classical Chinese and concludes that in Classical Chinese imperative verbs (=verbs of command) like 請 qing 'ask,' 令 ling 'order,' 勸 quan 'urge,' 教 
jiao 'cause,' 謂 wei 'call,' 命 ming 'order,' 求 qiu 'beg,' 召 zhao 'summon' are frequently followed by embedded structures containing the prohibitive negators (無 $w u$, 冊 $w u$, 勿 $w u$ ) which begin with a *m- initial, while causative verbs (e.g. 使 shi 'cause,' 令 ling 'order,' 助 zhu 'help,' 遣 qian 'send,' 送 song 'send') and verbs of sending are frequently followed by embedded structures containing simple negators (不 $b u$, 弗 $f u$, 非 $f e i$, 否 $f o u$ ), which begin with a *p- initial. The following examples are taken from Yue (1999):

(7) Verbs of command with *m-initial negators
a. 公 命 我勿 敢 言。
Gong ming wo wu gan yan.
Duke order 1 SG m-NEG dare speak

'The duke commanded us not to dare to speak (about it).'

(The Book of Shang, Jinteng)

b. 長魚矯 請 無 用 眾。

Chang yu jiao qing wu yong zhong.

Changyujiao ask m-NEG mobilize mass

'Changyujiao asked (the duke) not to mobilize the masses.'

(Zuozhuan Cheng 17.10)

(8) Causative verbs with *p- initial negators

a. 使人不偷。

Shi ren bu tou.

cause people p-NEG lazy

'Make people not lazy.'

(Xunzi Fuguo)

$\begin{array}{lll}\text { b. 人 之 } & \text { 彥, } \\ \text { Ren zhi } & \text { yan } \\ \text { People POSS } & \text { virtu } \\ \text { 俾 不 } & \text { 達。 } \\ \text { bi bu } & \text { da. }\end{array}$

Cause p-NEGreach out

'(As for) the sage and the virtuous of people, (he) turns against them, causing (them) not to (be able to) reach out'.

(The Book of Shang, Qin Shi)

Yue's thorough examination of ten Pre-Qin texts shows that, with very few exceptions, ${ }^{*}$ m-initial negators occur with verbs of command and ${ }^{*}$ - initial negators occur with causative verbs in general.

\section{Arguments against Yue (1999)}

Yue's proposed underlying structure, which suggests that there is no object control, is not without problems. Aside from the fact that the existence of embedded 
imperatives being extremely controversial, there are a few language-internal problems that cast doubt on Yue's analysis.

First, it is not clear why the covert second person pronoun must be unpronounced, and when it is pronounced, the resulting string becomes ungrammatical. I assume this is because the pronounced pronoun now appears in a position where PRO should be. PRO is traditionally analyzed as being in a caseless position because $\mathrm{T}$ in the embedded clause is nonfinite. However, Yue's analysis of a covert second person pronoun actually suggests finiteness in the object-controlled embedded clause and predicts that the subject can be overt, contra fact. The ungrammaticality of (9), in which the overt second pronoun renders the sentence illicit, should suggest its nonfiniteness.

(9) Wo jiao Zhangsan $[(*$ ni) zuo].

1SG ask Zhangsan 2SG sit

'I asked Zhangsan to sit.'

Second, Yue's analysis cannot explain the presence of partial control ${ }^{1}$ (see Landau 2004) in complements to verbs of command. Partial control is allowed when the predicate is modified by the adverb yiqi "together.' Yue's analysis assumes an unpronounced second person pronoun subject in the embedded clause, which is bound by the matrix object. If this analysis is correct, then it necessarily precludes the possibility of partial control. However, we do find partial control in complements to verbs of command.

(10) a. Zhangsan ${ }_{\mathrm{i}}$ jiao Lisi $_{\mathrm{j}}$ yiqi wan youxi.

Zhangsan ask Lisi together play game

'Zhangsan asked Lisi to play a game together.'

b. Zhangsan ${ }_{\mathrm{i}}$ jiao Lisi $_{\mathrm{j}}\left[e_{\mathrm{i}+\mathrm{j}}\right.$ yiqi wan youxi].

Third, since the bulk of Yue's arguments centers on the special negator bie, which appears in matrix negative imperatives, it begs the question of why the polite imperative marker qing 'please' can never occur in the embedded context. In Mandarin, a polite imperative marker can appear before or after the second person addressee.

(11) a. (Ni) zuo hao!

2SG sit properly

'Sit properly!'

\footnotetext{
${ }^{1}$ Partial control is a phenomenon discussed in Landau (2004), in which he discusses examples like (i) where PRO does not only refer to the controller.

(i) The chair ${ }_{i}$ preferred $\left[\mathrm{PRO}_{\mathrm{i}+\mathrm{j}}\right.$ to gather at 6] (Landau 2004:833).

Landau claims that desiderative, interrogative, factive, and propositional verbs are able to select partial control complements.
} 
$\begin{array}{llll}\text { b. Qing } & \text { (ni) } & \text { zuo hao! } \\ \text { IMP:AFF } & \text { 2SG } & \text { sit } & \text { properly }\end{array}$

'Please sit properly!'

c. Wo qing ni zuo hao!

$1 \mathrm{SG}$ ask 2SG sit properly

'I ask you to sit properly.'

d. (Ni) qing zuo hao!

2SG IMP:AFF sit properly

'Please sit properly!'

I argue that this marker qing is lexically ambiguous as it can be a verb meaning 'to ask' or an imperative marker occupying the $\mathrm{C}$ head position meaning 'please.' In (11c) it can only be analyzed as an object control verb with the DP wo ' $I$ ' being the subject. In (11b), the word class of qing is ambiguous as one could claim it is a verb with its subject (or topic) dropped ${ }^{2}$ or it is an imperative complementizer. When we consider (11d), it can only be interpreted as a polite imperative marker, because qing can appear after the addressee - a topicalized 2SG subject.

While the history of the evolution of qing is beyond the scope of this paper, there is no question that in older forms of Chinese, it started out as a verb ${ }^{3}$ and

${ }^{2}$ This is not a problem especially for a topic-drop language like Chinese in which subjects and objects can be freely dropped as long as the discourse allows it.

${ }^{3}$ In Wang Li's (2000) Dictionary of Archaic Chinese, there are three verbal meanings of 請 qing. The two other usages are nominal.

(i) To meet:

豪 傑之外多之交諸侯者, 常 請之。

Hao jie zhi wai duo jiao zhu hou zhe chang qing Zhi.

Hero elite GEN outside frequent acquaint marklords always meet 3.ACC

'Aside from heroes and elites he also make friends with marklords, and he always meets with them.'

(ii) To ask:

(Mozi, Haoling)

$\begin{array}{llllll}\text { 严 請 於 武 公, 公 不 許。 } \\ \text { Qi } \quad \text { qing } & \text { yu } \mathrm{Wu} \text { gong gong bu xu. } \\ \text { earnestly ask from } \mathrm{Wu} \text { Duke } & \text { Duke NEG } & \text { agree } \\ \text { 'He earnestly asked Duke Wu (for something). The Duke did not allow it.' }\end{array}$

(Zuozhuan, First year of Duke Yin)

(iii) To invite:

迺 置 酒 請 之。
Nai zhi jiu qing zhi.
then place wine invite 3.ACC
'Then he prepared the wine and invited him.'

(Hanshu, Xiaoxuanxu Huanghou Zhuan) 
gradually became a functional element marking polite imperatives. ${ }^{4} \mathrm{My}$ speculation is that over time the object control verb qing took on an extra meaning 'to ask.' Since the second person addressee is always dropped in discourse, qing was then reanalyzed as being the polite imperative operator in C. Note that this does not happen to similar verbs like qiu 'beg':

(12) a. (Ni) qing ta jin-qu zuo ba! 2SG invite 2SG go-in sit EMP 'Invite/Ask him to go in and have a seat!'

b. (Wo) qing ni gen wo jiehun! 1SG ask/IMP:POL 2SG with 1SG marry

When subject is pronounced: 'I ask that you marry me!'

When subject is dropped: 'Please marry me!'

c. Qing (ni) gen wo jiehun!

d. (Ni) qing gen wo jiehun!

(13) a. (Ni) qiu laoshi gei ni jige ba! 2SG beg teacher let 2SG pass EMP

'Beg your teacher to give you a passing grade!'

b. (Wo) qiu ni gen wo jiehun. 1SG beg 2SG with me marry 'I beg you to marry me.'

c. Qiu *(ni) gen wo jiehun!

d. *(Ni) qiu gen wo jiehun!

In $(13 \mathrm{c}, \mathrm{d})$, we notice that in the case of qiu the addressee cannot be dropped. This indicates that it has not yet grammaticalized into an imperative operator.

${ }^{4}$ This is speculative. However, I must mention that even in the early text Zuozhuan (before 389 BC) the word class of 請qing is already ambiguous. Wang Li (2000) notes that qing can appear before verbs to carry two meanings:

(i) To ask somebody to do something for you.

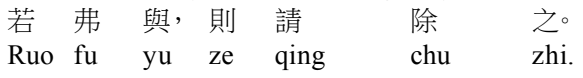

If NEG give then ask/please eliminate 3.ACC

'If he doesn't give it to you, then I ask you (or please) eliminate him.'

(Zuozhuan, First year of Duke Yin)

(ii) To ask to be allowed to do something for others.

臣 請 事 之。
Chen qing shi zhi.
I ask serve 3.ACC
'I the vassel ask to serve it.'

(Zuozhuan, First year of Duke Yin) My speculation is that the above uses are still verbal. (i) could be object control, with the object omitted. (ii) could be subject control. The two uses later get reanalyzed as the polite imperative mood marker in $\mathrm{C}^{0}$. 
Returning to our discussion of complements of verbs of command, we see that in Modern Chinese qing never appears in the embedded complements of verbs of command.

(14) *Wo jiao Zhangsan qing ${ }^{5}$ chi.

1SG ask Zhangsan IMP:POL eat

'I asked Zhangsan to please eat.'

Therefore, it remains a question why the special form of the imperative negator bie is kept in embedded imperatives but the positive imperative marker cannot surface. It certainly leaves a lot to be desired and it also leads one to wonder whether bie is really marking imperative.

The last piece of evidence comes from binding facts. Tang (1989) points out that the reflexive ziji 'self' in Chinese exhibits the blocking effect, which only permits long-distance binding if all intermediate subjects agree in person. The following examples in (15) are taken from Pan (2001).

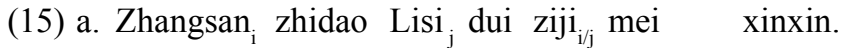

Zhangsan know Lisi to self not-have confidence

'Zhangsan knows that Lisi has no confidence in him/himself.'

b. $\mathrm{Wo}_{\mathrm{i}}$ juede $\mathrm{ni}_{\mathrm{j}}$ dui $\mathrm{ziji}_{*_{\mathrm{i} j \mathrm{j}}}$ mei xinxin.

I think you to self not-have confidence

'I think you have no confidence in yourself/*me.'

c. $\mathrm{Ni}_{\mathrm{i}}$ juede wo dui ziji $_{*_{i j}}$ mei xinxin ma?

'Do you think I have no confidence in myself/*you?'

d. Zhangsan ${ }_{\mathrm{i}}$ juede $\mathrm{wo} / \mathrm{ni}_{\mathrm{j}}$ dui $\mathrm{ziji}_{*_{\mathrm{ij}}}$ mei xinxin.

Zhangsan think $\mathrm{I} / \mathrm{you}$ to self not-have confidence

'Zhangsan thinks I/you have no confidence in myself/yourself/*him.'

Long distance binding is allowed in (15a) because all the intervening subjects are in third person. In (15 b-e), long-distance binding is barred because the intervening subjects do not agree in person.

(16) Zhangsan ${ }_{\mathrm{i}}$ kenqiu Lisi $_{\mathrm{j}}\left[{ }_{\mathrm{CP}}\right.$ bie jiegu $\left.\mathrm{ziji}_{\mathrm{ij}}\right]$.

Zhangsan beg Lisi NEG fire oneself

'Zhangsan begged Lisi not to fire him(self).'

5 Note that any attempt to classify qing as an adverb also fails because the verb chi can be modified by an adverb.

(i) Wo jiao Zhangsan tiantian chi.

1SG ask Zhangsan every day eat

'I asked Zhangsan to eat every day.' 
In (16), all the intervening subjects agree in the [person] feature. The possibility of long-distance binding suggests the absence of a blocking effect. One can take this to be evidence that the embedded subject cannot be second person; otherwise we should expect long-distance binding of ziji by the subject Zhangsan to fail.

\section{Verbs of command as object control verbs}

In the previous section, it is established that pivotal constructions involving verbs of command cannot have a silent second person subject. In fact, there is a lot of synchronic and diachronic evidence showing that verbs of command are object control verbs.

(17) a. Laoshi quan wo zuo gongke. teacher urge me do homework 'The teacher urged me to do homework.'

b. Laoshi quan $\mathrm{wo}_{\mathrm{i}} \mathrm{C}_{\mathrm{CP}} \mathrm{PRO}_{\mathrm{i}}$ zuo gongke].
Zhangsan qiu bangfei fang-le ta de mao. Zhangsan begged kidnappers release-PERF 3SG POSS cat
'Zhangsan begged the kidnappers to release his cat.'
b. Zhangsan qiu bangfei ${ }_{i}\left[_{\mathrm{CP}} \mathrm{PRO}_{\mathrm{i}}\right.$ fang-le ta de mao].

In (17) and (18), the matrix verbs assign a theta role to their object DPs. In turn, this DP controls PRO, which receives a theta role from the verb in the embedded clause. Evidence that the "pivot" DP receives a theta-role from the object control verb in (17) and (18) comes from the selectional restrictions that the verb of command places on the "pivot" DP. It is assumed that this pivot DP receives a THEME role from the verb. Object control verbs usually require the THEME to be animate as directive verbs are generally used with inanimate objects. Example (19) is semantically odd because the THEME is inanimate.

(19) \#Zhangsan quan huar zhang gao yidian.
Zhangsan urge flower grow tall a little
'Zhangsan urged the flower to grow a little taller.'

However, when the object control verb is replaced with a raising verb like yao 'want', the semantic anomaly disappears. In (20), the "pivot" DP huar 'flower' does not receive a THEME role from the matrix verb as it assigns its theta role to the entire proposition $\mathrm{CP}$.

(20) Zhangsan yao huar zhang gao yidian.

Zhangsan wants flower grow tall a little

'Zhangsan wants the flower to grow a little faster.'

In Classical Chinese, Aldridge (in press) shows that quantified DPs could never 
occur in an object position. The fact that a quantified DP could appear directly after a matrix verb suggests that it was the subject of the embedded clause. (21) is therefore a raising construction.

(21) 使 ${ }_{\mathrm{TP}}$ 或 美 $],\left[_{\mathrm{TP}}\right.$ 或 惡 $]$ 。
Shi huo mei huo e.
Make some beautiful some ugly
'Make some of them beautiful and some of them ugly.'

(Xunzi 106)

In Classical Chinese, 教 'cause' is an object control verb. We do not see any quantified DPs appearing after 教. Can this diagnostic be extended to Modern Chinese? Although most quantifiers in modern dialects in China no longer maintain the same distribution as above, there exists a kind of quantified DPs that cannot occur in the object position in Cantonese. In Cantonese, most native speakers do not allow reduplicated classifiers, which have the meaning of "each and every" to act as the 'pivot' of an object control sentence. Example (22a) sounds at best marginal to most speakers, and outright ungrammatical to some. It can only be grammatical if the first of the reduplicated classifiers is replaced with the strong quantifier mui 'every'.

(22) a. ??Lousi giu

go go tunghok dou jatcai coeng go. teacher ask CL CL student FOC together sing song 'The teacher asked each and every student to sing together.'

b. Lousi giu muigo tunghok dou jatcai coeng go. teacher ask Q CL student FOC together sing song 'The teacher asked every student to sing together.'

However, reduplicated classifiers can appear in a raising construction, as in (23), or in (24), where the verb selects a CP proposition. This suggests that the quantified DPs with reduplicated classifiers in both sentences are the subjects of the embedded clauses. The differences shown in (22) and (23-24) support our claim that verbs of command are object control verbs.

(23) Lousi jiu go go tunghok dou jatcai coeng go. teacher want CL CL student FOC together sing song 'The teacher wants each and every student to sing together.'

(24) Lousi soeng go go tunghok dou geidak dai syu. teacher hopes CL CL student FOC remember bring book 'The teacher hopes every student remembered/will remember to bring his/her book.'

\footnotetext{
${ }^{6}$ This example is taken from Aldridge (in press).
} 


\section{Bie as an indicator of deontic modality}

It is now a good time to discuss why the negator bie occurs in both embedded complements of verbs of command and imperative clauses, since the bulk of Yue's (1999) account centers on this fact. While a full syntactic analysis of bie is beyond the scope of this paper, I will attempt to show that bie marks deontic modality and may indicate irrealis (see also Aldridge, in press) or even the subjunctive mood.

The well-attested etymology of the imperative negator bie is that it came from the negated form of the modal verb yao 'will/must', which means that bie is the phonologically reduced form of the simple negator BU + modal yao (Zev Handel, personal communication). While it is true that bie mostly shows up in imperative sentences, it is certainly not the only environment in which bie can appear. Consider the sentences in (25), in which all instances of bie can be substituted for by BU + yao. One thing that should be obvious to the reader is that in all three sentences bie appears with a third person subject. This is surprising, considering that crosslinguistically imperatives generally pose a restriction on the person feature of the subject so that the subject can only be [+second person]. As it turns out, bie in all the following sentences expresses deontic modality?
Zhangsan qianwan bie zuo shashi a! Zhangsan by all means NEG do silly matter EMPH '(I hope) Zhangsan won't commit suicide by all means!'
b. Yinger bie tai zao chi naifen. baby NEG too early eat powdered milk
'Babies shouldn't drink powdered milk too early.'
c. Wo xiwang manlian bie shu a! I hope Manchester NEG lose EMPH 'I hope Manchester United will not lose!'

Another fact that should be addressed is that in all the above sentences, the subjects of the clauses immediately containing bie are not the addressees of the utterances. Imagine that Zhangsan is a famous celebrity. In this scenario, (25a) could be uttered by a fan who just read on the tabloid news that Zhangsan is suffering from some mental illnesses, which may cause him to hurt himself. (25b) is a warning to all parents, and it certainly is not addressed to any baby in the speaker's mind. (25c) is probably uttered by a soccer fan who wished that his favorite team, Manchester United, would not lose in the upcoming game. It is clear that the data in (25) all involve irrealis - they express emotions, personal opinions, and wishes about things that have not come true at the time of utterance. They can never be taken to be imperative clauses, as there is no command being made.

\footnotetext{
${ }^{7}$ The imperative is an example of deontic modality.
} 
Moreover, recall that I proposed earlier that qing is an optional polite imperative marker in Mandarin Chinese. We notice that once qing is inserted in the above sentences, the imperative interpretation is forced upon them and the subject of the clauses containing bie suddenly becomes the addressee, as in (26). This fact is strong evidence for our proposal that bie does not mark the imperative mood.

(26) a. Zhangsan qing qianwan bie zuo shashi a!

Zhangsan please by all means NEG do silly-matter EMPH

'Zhangsan, please do not commit suicide by all means!'

b. Yinger qing bie tai zao chi naifen.

baby please NEG too early eat powdered milk

'Babies, please don't drink powdered milk too early.'

c. Manlian qing bie shu a!

Manchester please NEG lose EMPH

'Manchester, please do not lose!'

Finally, recall from my previous summary of Yue (1999) that imperative clauses in Archaic Chinese generally deployed an m-initial negator (e.g. 無, 冊, 勿), while nonimperative clauses use a p-initial negator. However, even in Archaic Chinese, it is clear that certain m-initial negators are used in clauses that do not express commands.

(27) 十九 年春, 諸侯還自沂上，

Shi jiu nian chun, zhu hou hai zi Yishang,

Nineteen year spring marklords return from Yishang

盟於督揚, 日：「大册侵小。」

meng yu Duyang, yue da wu qin xiao.

ally at Duyang say big m-NEG invade small

'The nineteenth year, spring, the markloads returned from Yishang and formed an alliance in Duyang, saying, "big states do/should not invade small states.",

(Zuozhuan, Duke Xiang, 19th year)

(28) 君子 食 pro $_{i}$ 無求飽。

Junzi shi wu qiu bao.

Lordling eat m-NEG seek full

'When a lordling eats, he does not seek to stuff himself.'

(Lunyü, Xue'er)

(29) 襄仲欲勿哭。

Xiang zhong yü wu ku.

Xiangzhong desire m-NEG cry

'Xiangzhong desires to not cry.' 
A few scholars have pointed out that $\mathrm{m}$-initial negators are used in nonindicative clauses. Van Auken (2004), for example, noted that in Classical Chinese the $\mathrm{m}$-initial negators (無/册) are not limited to imperative or prohibitive uses; they also occur in other sentence types including those expressing ability, counterfactual, or subjunctive propositions. Therefore, one possibility is to argue that the so-called embedded imperatives are really nonindicative clauses.

In Romance and Balkan languages, verbs of command and verbs of volition often select a subjunctive complement, as in the Spanish data in (30).

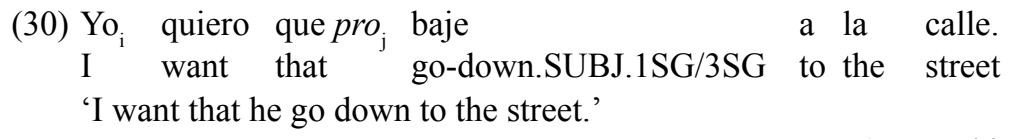

(Kempchinsky 2009)

That deontic modality can be expressed in complements following volitional and verbs of command is not an anomaly. Embedded complements of such verbs, which express commands, requests, suggestions, or desires are typically expressed in the Romance and Balkan languages. Furthermore, in Spanish, imperative verbs cannot be negated, as in (31). Negative imperatives must be expressed using the subjunctive mood. This seems to mirror the situation in Chinese where bie is used for negative imperatives.

(31) Spanish
a. *No lee
lo.
NEG read-2sg.Imp it
'Don't read it!'
b. No lo leas.
NEG it read-2sg.Subj
'Don't read it!'

A similar phenomenon is also observed in Modern Greek, in which the subjunctive form that is normally used for embedded subjunctive clauses is used to make direct commands.

(32) Modern Greek
a. $\mathrm{O}$ Yannis se dietakse na $\min$ to grapsis.
The Yannis you ordered-2sg NA Neg it write-2sg.Subj

'Yannis ordered you not to write it.'

(=(48a) in Han 2001)

b. $\mathrm{Na} \min$ to grapsis.

NA Neg it write-2sg.Subj

'Don't write it!' 
Summing up, the Chinese data in this section clearly shows that bie expresses deontic modality or irrealis. Furthermore, bie also appears in syntactic contexts where the subjunctive mood is used in other languages. The claim that Chinese also has subjunctive mood may be controversial and premature at this point. I, therefore, leave it for further research. However, it is evident that the negator bie is not limited to imperative use, and its appearance in embedded complements of verbs of commands does not indicate that these embedded complements are imperative clauses.

\section{Conclusion}

This paper argues against Yue's (1999) view that complements to verbs of commands (jiao 'to ask/to tell,' qing 'to request,' quan 'to persuade,' etc.) are embedded imperatives with a covert [ + second person] subject pronoun. Evidence against the embedded imperative analysis include the presence of partial control, the absence of blocking effect in long-distance binding, the incompatibility between these complement clauses and the polite imperative marker qing, and the fact that Yue's proposed covert [+second person] pronoun cannot be made overt. Since verbs of commands participate in object control, the present proposal agrees with Zhu's (1982) treatment of verbs of command as pivotal verbs. Finally, complement clauses of verbs of command are not embedded imperatives as bie can also appear with the third person subjects, which shows that the negator does not mark imperative but irrealis and deontic modality. Hence, its presence in complements of verbs of command does not lead to an embedded imperative analysis.

\section{References}

Aldridge, Edith. In press. ECM and Control in Archaic Chinese. In Barbara Meisterernst (ed.), New aspects of Classical Chinese grammar (Asian and African Studies of The Humboldt University of Berlin). Wiesbaden: Harrassowitz.

Han, Chung-hye. 2001. Force, negation and imperatives. The Linguistic Review 18. 289-325.

Kempchinsky, Paula. 2009. What can the subjunctive disjoint reference effect tell us about the subjunctive? Lingua 119(12). 1788-1810.

Landau, Idan. 2004. The scale of finiteness and the calculus of control. Natural Language and Linguistic Theory 22(4). 811-877.

Pan, Haihua. 2001. Why the blocking effect? In Peter Cole, James Huang \& Gabriella Hermon (eds.), Syntax and semantics: Long distance reflexives. 279-316. New York: Academic Press.

Platzack, Christer. 2007. Embedded imperatives. In Wim van der Wurff (ed.), Imperative clauses in generative grammar: Studies in honour of Frits Beukema, 181-203. Amsterdam, Netherlands: Benjamins.

Tang, C.-C. Jane. 1989. Chinese reflexives. Natural Language and Linguistic Theory 7(4). 93-121.

Van Auken, Newell Ann. 2004. The modal negative wu in Classical Chinese. In 
Takashima Ken'ichi \& Jiang Shaoyu (eds.), Meaning and form: Essays in premodern Chinese grammar and semantics, 91-210. München: Lincom Europa.

Wang Li (ed.). 2000. Gu Hanyu Zidian [Dictionary of Old Chinese]. Beijing: Zhonghua Shuju.

Yue, Anne O. 1999. The so-called pivotal construction in pre-Qin Chinese. In Alain Peyraube \& Chaofen Sun (eds.), In honor of Mei Tsulin: Studies on Chinese historical syntax and morphology, 327-360. Paris: Ecole des Hautes Etudes en Sciences Sociales, Centre de Recherches Linguistiques sur l'Asie Orientale.

Zhu, Dexi. 1982. Yufa Jiangyi [Lectures on Chinese Grammar]. Beijing: Shangwu Yinshu Guan.

Mailing address: Department of Linguistics, University of Washington, Box 352425 Seattle, WA 98195-2425, USA

Email: $\quad$ columyip@uw.edu

Received: $\quad$ November 5, 2015

Accepted: $\quad$ March 17, 2016 


\title{
論漢語中的〔使役動詞＋補足語〕結構
}

\author{
葉澤林 \\ 西雅圖華盛頓大學
}

\section{提要}

本文對漢語中〔使役動詞＋補足語〕是否屬於兼語式結構作出進一步探討。余藹芹 (1999) 指出使役動詞（如“叫”、“請”、“勸”）的補足語應為嵌人祈使句, 而 這種嵌入祈使句都有隱藏〔十第二身〕主語。本文認為隱藏主語必為第二身這個觀 點是不成立的。首先, 此類補足語不能與祈使句標記 “請” 共存。其次, 他們的主 語可以被部份控制。再次, 他們也沒有長距離約束下的阻塞效應。最後, 這些主語 必須隱藏。由於使役動詞可以參與賓語控制, 我們認為朱德熙 (1982) 把〔使役動詞 十補足語了結構分析為兼語式是正確的。我們亦指出否定詞「別」表達的並非祈使 情態而是非現實情態或道義情態。

\section{關鍵詞}

嵌入祈使句，兼語式，祈使否定詞，賓語控制，道義情態 